\title{
Post-transplant inflow modulation for early allograft dysfunction after living donor liver transplantation
}

\author{
Mohamed Elshawy ${ }^{1,2}$, Takeo Toshima ${ }^{1 *} \mathbb{D}$, Yoshiki Asayama ${ }^{3}$, Yuichiro Kubo $^{3}$, Shinichiro Ikeda ${ }^{1}$, Toru Ikegami ${ }^{1}$, \\ Shingo Arakaki ${ }^{4}$, Tomoharu Yoshizumi ${ }^{1}$ and Masaki Mori ${ }^{1}$
}

\begin{abstract}
Background: To treat small-for-size syndrome (SFSS) after living donor liver transplantation (LDLT), many procedures were described for portal flow modulation before, during, or after transplantation. The selection of the procedure as well as the best timing remains controversial.

Case presentation: A 43-year-old female with end-stage liver disease underwent LDLT with extended left with caudate lobe graft from her donor who was her 41-year-old brother (graft volume/standard liver volume (GV/SLV), 35.7\%; graft to recipient weight ratio (GRWR), 0.67\%). During the surgery, splenectomy could not be performed owing to severe peri-splenic adhesions to avoid the ruined bleedings. The splenic artery ligation was not also completely done because it was dorsal to the pancreas and difficult to be approached. Finally, adequate portal vein (PV) inflow was confirmed after portal venous thrombectomy. As having post-transplant optional procedures that are accessible for PV flow modulation, any other procedures for PV modulation during LDLT were not done until the postoperative assessment of the graft function and PV flow for possible postoperative modulation of the portal flow accordingly. Postoperative PV flow kept as high as $30 \mathrm{~cm} / \mathrm{s}$. By the end of the 1st week, there was a progressive deterioration of the total bilirubin profile (peak as $19.4 \mathrm{mg} / \mathrm{dL}$ ) and ascitic fluid amount exceeded $1000 \mathrm{~mL} /$ day. Therefore, splenic artery embolization was done effectively and safely on the 10th postoperative day (POD) to reverse early allograft dysfunction as PV flow significantly decreased to keep within $20 \mathrm{~cm} / \mathrm{s}$ and serum total bilirubin levels gradually declined with decreased amounts of ascites below $500 \mathrm{~mL}$ on POD 11 and thereafter. The patient was discharged on POD 28 with good condition.
\end{abstract}

Conclusions: SFSS can be prevented or reversed by the portal inflow modulation, even by post-transplant procedure. This case emphasizes that keeping accessible angiographic treatment options for PV modulation, such as splenic artery embolization, after LDLT is quite feasible.

Keywords: Liver transplantation, Portal flow, Modulation, Graft dysfunction, Small-for-size syndrome, Splenic artery, Embolization

\footnotetext{
* Correspondence: toshima@surg2.med.kyushu-u.ac.jp

${ }^{1}$ Department of Surgery and Science, Graduate School of Medical Sciences,

Kyushu University, 3-1-1 Maidashi, Higashi-ku, Fukuoka 812-8582, Japan

Full list of author information is available at the end of the article
}

\section{Springer Open}

(c) The Author(s). 2020 Open Access This article is licensed under a Creative Commons Attribution 4.0 International License, which permits use, sharing, adaptation, distribution and reproduction in any medium or format, as long as you give appropriate credit to the original author(s) and the source, provide a link to the Creative Commons licence, and indicate if changes were made. The images or other third party material in this article are included in the article's Creative Commons licence, unless indicated otherwise in a credit line to the material. If material is not included in the article's Creative Commons licence and your intended use is not permitted by statutory regulation or exceeds the permitted use, you will need to obtain permission directly from the copyright holder. To view a copy of this licence, visit http://creativecommons.org/licenses/by/4.0/. 


\section{Introduction}

Living donor liver transplantation (LDLT) is a commonly used treatment option for patients with end-stage liver disease, particularly in eastern countries [1, 2]. Small-for-size syndrome (SFSS) can lead to serious early graft dysfunction after LDLT. The main clinical presentation is cholestasis, prolonged ascites, coagulopathy, and encephalopathy [3]. Extra small graft, portal hyperperfusion, severe portal hypertension, and venous outflow obstruction are the main underlying causes of SFSS [4]. To prevent or reverse this drastic complication, many procedures were described for portal flow modulation before, during, or after the transplant surgery; however, the selection of the procedure as well as the best timing is still controversial [5-9].

Herein, we report a case of LDLT recipient who developed early graft dysfunction after LDLT and SFSS with evident high portal flow. Postoperative splenic artery embolization (SAE) was done as a post-transplant portal inflow modulation, and SFSS was successfully treated.

\section{Case presentation}

The patient was a 43-year-old female with end-stage liver disease secondary to $\mathrm{HCV}$ hepatitis. Her weight was $60 \mathrm{~kg}$ and her body mass index was $24.3 \mathrm{~kg} / \mathrm{m}^{2}$. Her blood type was $\mathrm{O} R \mathrm{Rh}(+)$. Preoperative assessment reveals the Child-Pugh score was grade $\mathrm{C}$ as 13 pts and the model for end-stage liver disease score was high as 19. Radiological evaluation revealed partial PV thrombosis in the main trunk. She underwent partial SAE 8 years ago and umbilical hernia repair. Her donor was her 41-year-old brother who weighted $79 \mathrm{~kg}$ and body mass index was $26.7 \mathrm{~kg} / \mathrm{m}^{2}$. His blood type was B Rh (+). Preoperative 3-dimensional volumetry revealed that the extended left with caudate lobe graft volume was 555 $\mathrm{mL}$, which was $49.2 \%$ of the recipient standard liver volume (SLV). The donor and recipient have incompatible blood types, so the recipient was subjected to preoperative rituximab protocol.

The patient underwent LDLT using extended left with caudate lobe graft. The actual graft weighted $467 \mathrm{~g}$ (402 $\mathrm{g}$ after UW reperfusion) of which GV/SLV was $35.7 \%$ and GRWR was $0.67 \%$. It had middle and left hepatic veins, left hepatic artery, left PV, and left hepatic duct. Upon laparotomy, there was $10,500 \mathrm{~mL}$ of ascites as well as perihepatic adhesions and periumbilical adhesions. On laparotomy, portal venous pressure (PVP) monitoring was $22 \mathrm{mmHg}$. The splenic artery was dorsal to the pancreas and difficult to be approached, and finally, the upper pole branch of the splenic artery was identified and ligated at the level of the distal pancreas, by which only the upper pole of the spleen turned pale. Splenectomy could not be performed due to severe peri-splenic adhesions to avoid the ruined bleedings. After PV thrombectomy was done, adequate PV inflow was not confirmed until left gastric vessel ligation was performed. After graft reperfusion, PVP was $20 \mathrm{mmHg}$ but PV flow was relatively low, $520 \mathrm{~mL} / \mathrm{min}$. At this time, we choose not to ligate the other branches of the splenic artery nor the lienorenal shunt until postoperative assessment of the graft function and the PV flow for possible postoperative modulation and boost of the portal flow accordingly. The point is that safe angiographic procedures for portal flow modulation are accessible postoperatively, such as splenic artery embolization for portal decompression and balloon-occluded retrograde transvenous obliteration (BRTO) for boosting portal flow.

After LDLT, routine abdominal ultrasound screening revealed that portal flow was $60 \mathrm{~cm} / \mathrm{s}$ on POD 1, then it kept as high as $30 \mathrm{~cm} / \mathrm{s}$ along the 1 st week (Fig. 1a). Ascites volume was initially below $1000 \mathrm{~mL} /$ day till 6th POD, however, increased markedly thereafter. Serum bilirubin levels showed a stepwise gradual increase that reaches $19.4 \mathrm{mg} / \mathrm{dL}$ on POD 9 (Fig. 2). Platelet counts were lowest $\left(42 \times 10^{3} / \mu \mathrm{L}\right)$ by POD 8 and INR levels kept below 1.5 along the whole clinical course. Considering this relatively insufficient graft volume along with the clinical and laboratory parameters suggestive of SFSS, then we decided to do splenic artery embolization (SAE) for portal decompression. The patient underwent arterial splenic angiography on POD 10 via percutaneous transfemoral Seldinger's technique. After angiographic assessment, partial SAE occluding the main branch of the splenic artery was achieved by trans-catheter coil embolization (Fig. 1c, d). Dynamic computed tomography comparing the spleen pre- and postembolization are also shown (Fig. 1e, f).

After SAE, PV flow significantly decreased to keep within $20 \mathrm{~cm} / \mathrm{s}$ by US study (Fig. 1b). Additionally, serum total bilirubin levels gradually declined and ascites amounts decreased below $400 \mathrm{~mL}$ (Fig. 2), and then, the abdominal drain was removed on POD 21. Platelet counts showed a stepwise increase thereafter. The patient was discharged on POD 28 in good condition without any infectious complications.

\section{Discussion}

SFSS is a catastrophic complication that can lead to graft failure and retransplantation [10]. The classic postoperative course is graft dysfunction within the first 2 posttransplant weeks with two of the following: prolonged functional cholestasis (serum total bilirubin levels $>5.0$ $\mathrm{mg} / \mathrm{dL})$, intractable ascites $(1000 \mathrm{~mL} /$ day $)$, and/or coagulopathy (INR > 2) [10-13]. SFSS should be differentiated from graft dysfunction due to other pathological abnormalities [14]. For instance, technical (e.g., arterial or portal occlusion, venous outflow congestion, bile leak), immunological (e.g., acute rejection after LDLT), and 

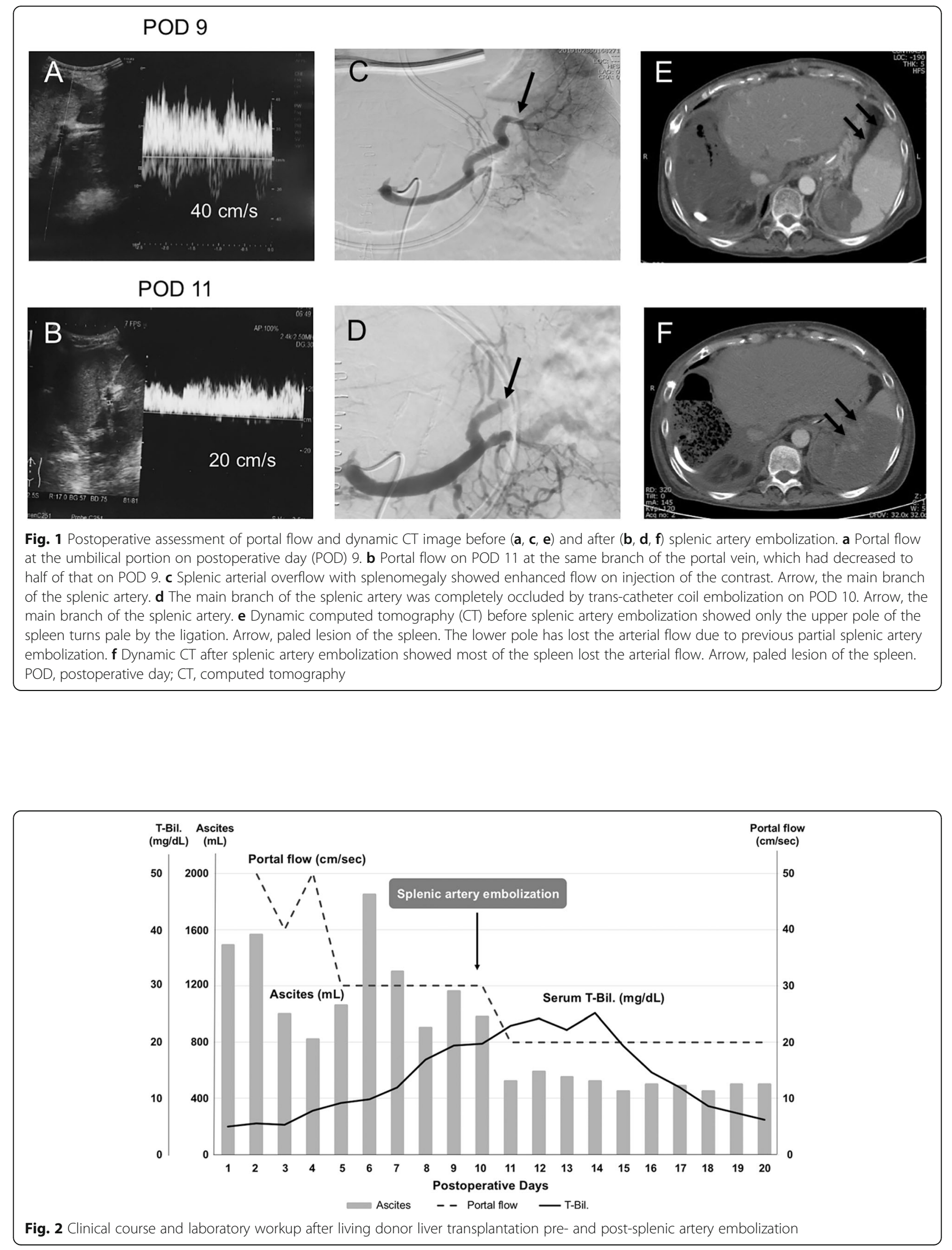
infectious (e.g., cholangitis, sepsis) abnormalities can lead to graft dysfunction and overlapped clinical presentation [11, 12]. Moreover, recent studies have documented that GRWR less than $0.8 \%$ or GV/SLV less than $40 \%$ do not necessarily lead to SFSS [15-19]. Indeed, multiple variables are attributed including preoperative recipient disease severity, donor age, portal pressure and/or flow, graft type, and graft regeneration $[3,17,20,21]$.

This case presents a patient who underwent ABOiLDLT using extended left with caudate lobe graft that was relatively insufficient as the GV/SLV $35.7 \%$ and at high risk of SFSS after the surgery. Early graft dysfunction was imminent giving progressive hyperbilirubinemia and intractable ascites. Radiological evaluation excluded technical problems that may be the cause of the clinical presentation. Liver transaminases were initially high; however, along the 1st postoperative week, a progressive decline towards near normal levels precludes possible acute rejection. Therefore, along with a high postoperative portal flow, SFSS diagnosis was highly suspected. Coagulopathy, represented by high prothrombin time and INR, may be along the clinical presentation of SFSS $[10,14]$. However, in their series, Gruttadauria et al. reported that coagulopathy was not a reliable indicator of SFSS [7]. In the present case, though INR values showed a slight increase before splenic artery embolization SAE, they were kept below 1.5 before as well as after portal flow modulation.

High post-perfusion PVP had been reported to negatively impact graft outcome $[22,23]$. In the setting of small-for-size graft after LDLT, persistent elevation of PVP causes direct hepatocyte injury due to sinusoidal shear stress, congestion, hemorrhage, and endothelial activation [24-26]. Indeed, secondary ischemic changes occur due to adaptive hepatic artery vasoconstriction [27]. A key management strategy is portal flow modulation with partially diverting portal flow via portosystemic shunt [28] and/or portal decompression by splenectomy $[3,29,30]$, splenic artery ligation $[29,31]$, or splenic artery embolization [7, 32, 33]. Following LDLT, maintaining adequate portal inflow is crucial for boosting graft regeneration [34]. In the setting of portal hypertensive liver cirrhosis, high sinusoidal resistance diverts portal flow, via portosystemic collaterals, which may jeopardize the graft [35]. Portal steal phenomenon can also occur due to hepatofugal diversion of portal flow through major $(>1 \mathrm{~cm})$ portosystemic shunts $[36,37]$ with subsequent graft ischemic injury and possible posttransplantation PV thrombosis [28, 38, 39].

We $[40,41]$ previously reported the beneficial effects of simultaneous splenectomy for recipients with PVP more than $15 \mathrm{mmHg}$ following graft reperfusion. In addition, we previously described that en bloc division of large portosystemic shunts along with splenectomy should simplify and normalize portal hemodynamics with the best graft outcome [42, 43]. On the contrary, the Tokyo University group reported that splenectomy was an independent predictor for postoperative hemorrhage and sepsis; hence, they restricted simultaneous splenectomy in strictly indicated recipients [44]. Moon et al. compared simultaneous splenectomy to an innovative technique, splenic devascularization in adult LDLT. A higher incidence of procedural-related complications was observed in the splenectomy group, as pancreatic fistula, abscess, and hemorrhage, though, did not reach statistical significance [45]. In the setting of LDLT, simultaneous splenectomy often leads to higher morbidity. In the present case, extensive peri-splenic adhesions put the patient at high risk for simultaneous splenectomy. Attempts to ligate the main splenic artery also make the patient at high risk for distal pancreatic injury which can lead to post-transplant catastrophic pancreatic complications. Moreover, following PV thrombectomy and reperfusion, as we previously described, PVP was relatively adequate [46]; however, PV flow was 520 $\mathrm{mL} / \mathrm{s}$. As we have the postoperative optional procedures that are accessible for portal flow modulation, then additional intraoperative procedures were not performed during LDLT until postoperative assessment of graft function and PV flow. For instance, SAE can be an alternative for portal decompression [7, 32, 33] and BRTO can be used for boosting portal hypoperfusion salvaging against portal steal preventing graft ischemia [47]. Postoperative portal hemodynamics were disturbed as PV inflow kept high along with marked intractable ascites and serum hyperbilirubinemia, then postoperative SFSS ensued. SAE effectively reversed early allograft dysfunction and impending SFSS.

Previous reports have already pointed to SAE for posttransplant portal modulation. For instance, Gruttadauria et al. [7] reported a series of six patients; however, all were right lobe graft with mean GRWR $1.282 \pm 0.276 \%$. Although the clinical presentation was nearly similar to this report, they did not refer to portal pressure nor flow in the peritransplant management. In the present case, the graft of extended left with caudate lobe was low as GRWR 0.67\%. After graft reperfusion, finally, PVP was relatively high as $20 \mathrm{mmHg}$, while PV flow was relatively low as $520 \mathrm{~mL} / \mathrm{min}$. Therefore, we choose to monitor portal hemodynamics and decide further management giving accessible angiographic options postoperatively.

Reported rates of complications after SAE, as splenic abscesses, splenic infarction, infections, bleeding, pancreatitis, or postembolization syndrome (abdominal pain, fever, and increased levels of pancreatic enzymes), widely vary $[48,49]$. In the setting of post-transplant SFSS, SAE is a safe and feasible option. Among 54 patients who 
underwent post-transplant SAE, Presser et al. [32] reported one case of post-splenectomy syndrome (transient leukocytosis and fever which resolve spontaneously shortly after SAE). The present case did not develop any post SAE complications.

Giving post-transplantation portal modulation dilemma [6, 9, 32, 50], postoperative portal modulation can be an alternative to high-risk intraoperative procedures. As portal hyperperfusion is contributed by splenic flow [7], an angiographic intervention can aid and may be more effective in post-transplant portal inflow modulation when necessary. For instance, the present case emphasizes that in the setting of relatively small-for-size graft, post-transplant portal decompression with splenic artery embolization can safely rescue from impending SFSS in case of increased portal inflow postoperatively.

\section{Conclusion}

We report here the case of a patient who recovered from SFSS by the postoperative portal flow modulation by splenic artery embolization. The present case suggests that keeping the accessible angiographic treatment options for PV modulation after LDLT is quite feasible.

\section{Abbreviations}

BRTO: Balloon-occluded retrograde transvenous obliteration; GRWR: Graft to recipient weight ratio; GV/SLV: Graft volume/standard liver volume; LDLT: Living donor liver transplantation; PV: Portal vein; PVP: Portal venous pressure; POD: Postoperative day; SFSS: Small-for-size syndrome; SAE: Splenic artery embolization

\section{Acknowledgements}

We would like to thank Edanz Company for the English language editing.

\section{Authors' contributions}

M.E. and T.T. participated in the writing of the manuscript and data analysis T.T. and T.I. participated in the research design. Y.A., Y.K., S.I., and S.A participated in data collection. T.I. and T.Y. reviewed it. T.Y. and M.M. contributed to the discussion and reviewed the manuscript. The authors read and approved the final manuscript.

\section{Funding}

This study was supported by the following 4 grants: the Program for Basic and Clinical Research on Hepatitis, from the Japan Agency for Medical Research and Development, AMED (Numbers 18fk0210023h0002 and 17fk0210305h0003) and JSPS KAKENHI, a Grant-in-Aid from the Ministry of Health, Labour and Welfare, Japan (Numbers JP-16 K10577).

The funding sources had no role in the collection, analysis, or interpretation of the data or in the decision to submit the article for publication.

\section{Availability of data and materials}

All data are available on request.

\section{Ethics approval and consent to participate}

All procedures used in this research were performed in accordance with the Helsinki Declaration of 1964, as revised in Brazil 2013.

\section{Consent for publication}

Written informed consent was obtained for the publication of this case report and accompanying images.

\section{Competing interests}

The authors declare that they have no competing interests.

\section{Author details}

'Department of Surgery and Science, Graduate School of Medical Sciences, Kyushu University, 3-1-1 Maidashi, Higashi-ku, Fukuoka 812-8582, Japan. ${ }^{2}$ Department of General Surgery, Faculty of Medicine, Ain Shams University, Cairo, Egypt. ${ }^{3}$ Department of Clinical Radiology, Graduate School of Medical Sciences, Kyushu University, Fukuoka, Japan. ${ }^{4}$ Department of Infectious, Respiratory, and Digestive Medicine, Graduate School of Medicine, University of the Ryukyus, Nakagami, Okinawa, Japan.

Received: 30 January 2020 Accepted: 5 June 2020

Published online: 08 July 2020

\section{References}

1. Ikegami T, Yoshizumi T, Soejima Y, et al. Feasible usage of ABO incompatible grafts in living donor liver transplantation. Hepatobiliary Surg Nutr. 2016;5(2):91-7.

2. Tanaka $\mathrm{K}$, Ogura $\mathrm{Y}$, Kiuchi $\mathrm{T}$, Inomata $\mathrm{Y}$, et al. Living donor liver transplantation: eastern experiences. HPB. 2004;6(2):88-94.

3. Yoshizumi T, Mori M. Portal flow modulation in living donor liver transplantation: review with a focus on splenectomy. Surg Today. 2019; 50(1):21-9.

4. Shoreem H, Gad EH, Soliman H, et al. Small for size syndrome difficult dilemma: lessons from 10 years single Centre experience in living donor liver transplantation. World J Hepatol. 2017;9(21):930-44.

5. Etesami K, Genyk Y. The increasingly limited basis for portal venous pressure modulation in living donor liver transplantation. Liver Transpl. 2018;24(11): 1506-7.

6. Yao $\mathrm{S}$, Kaido $\mathrm{T}$, Uozumi $\mathrm{R}$, et al. Is portal venous pressure modulation still indicated for all recipients in living donor liver transplantation? Liver Transplant. 2018;24(11):1578-88.

7. Gruttadauria S, Mandala L, Miraglia R, et al. Successful treatment of smallfor-size syndrome in adult-to-adult living-related liver transplantation: single center series. Clin Transpl. 2007;21(6):761-6.

8. Umeda Y, Yagi T, Sadamori H, et al. Effects of prophylactic splenic artery modulation on portal overperfusion and liver regeneration in small-for-size graft. Transplantation. 2008;86(5):673-80.

9. Ling XS, Koh YX, Teo JY, Goh BKP, Lee SYCP. Inflow modulation in adult living donor liver transplant to reduce risk of small-for-size syndrome (SFSS). Clin Surg. 2018;3:1-4.

10. Dahm F, Georgiev P, Clavien P. Small-for-size syndrome after partial liver transplantation : definition, mechanisms of disease and clinical implications. Am J Transpl. 2005;5(11):2605-10.

11. Ikegami T, Yoshizumi T, Sakata K, et al. Left lobe living donor liver transplantation in adults: what is the safety limit? Liver Transplant. 2016; 22(12):1666-75.

12. Hibi T, Kitagawa Y. Small-for-size syndrome in LT. Clin Liver Dis. 2017;10(4): 93-6.

13. Humar A, Beissel J, Crotteau S, Cohen M, Lake J, Payne WD. Delayed splenic artery occlusion for treatment of established small-for-size syndrome after partial liver transplantation. Liver Transpl. 2009;15(2):163-8.

14. Sugawara Y, Makuuchi M, Takayama T, et al. Small-for-size grafts in livingrelated liver transplantation. J Am Coll Surg. 2001;192(4):510-3.

15. Selzner M. A graft to body weight ratio less than 0.8 does not exclude adult-to adult right-lobe living donor liver transplantation. Liver Transplant. 2007;13(5):767-8.

16. Kaido T, Mori A, Ogura Y, et al. Lower limit of the graft-to-recipient weight ratio can be safely reduced to $0.6 \%$ in adult-to-adult living donor liver transplantation in combination with portal pressure control. Transplant Proc. 2011;43(6):2391-3.

17. Kiuchi T, Tanaka K, Ito T, et al. Small-for-size graft in living donor liver transplantation: how far should we go? Liver Transplant. 2003;9(9):29-35.

18. Yagi S, Uemoto S. Small-for-size syndrome in living donor liver transplantation. Hepatobiliary Pancreat Dis Int. 2012;11(6):570-6.

19. Hill MJ, Hughes M, Jie T, et al. Graft weight/recipient weight ratio: how well does it predict outcome after partial liver transplants? Liver Transplant. 2009; 15(9):1056-62.

20. Ikegami T, Shirabe K, Yoshizumi T, et al. Primary graft dysfunction after living donor liver transplantation is characterized by delayed functional hyperbilirubinemia. Am J Transplant. 2012;12(7):1886-97. 
21. Macshut $M$, Kaido $T$, Yao $S$, et al. Older donor age is a risk factor for negative outcomes after adult living donor liver transplantation using smallfor-size grafts. Liver Transplant. 2019;25(10):1524-32.

22. Ogura Y, Hori T, El Moghazy WM, et al. Portal pressure $<15 \mathrm{mmHg}$ is a key for the successful adult living donor liver transplantation utilizing smaller grafts than before. Liver Transplant. 2010;16(6):718-28.

23. Vasavada BB, Chen CL, Zakaria M. Portal flow is the main predictor of early graft dysfunction regardless of the GRWR status in living donor liver transplantation - a retrospective analysis of 134 patients. Int J Surg. 2014; 12(2):177-80.

24. Panis $Y$, McMullan DM, Emond JC. Progressive necrosis after hepatectomy and the pathophysiology of liver failure after massive resection. Surgery. 1997:121(2):142-9.

25. Cantré $D$, Schuett $H$, Hildebrandt $A$, et al. Nitric oxide reduces organ injury and enhances regeneration of reduced-size livers by increasing hepatic arterial flow. Br J Surg. 2008;95(6):785-92.

26. PTW K, GB K. Importance of hepatic flows in liver transplantation. J Hepatol Gastrointest Disord. 2016;02(02):127-32.

27. Lautt WW, Legare DJ, Ezzat WR. Quantitation of the hepatic arterial buffer response to graded changes in portal blood flow. Gastroenterology. 1990; 99:1024-8.

28. Toru I, Soejima Y, Taketomi A, et al. Living donor liver transplantation with extra-small graft; inflow modulation using splenectomy and temporary portocaval shunt. Hepatogastroenterology. 2008;55(82-83):670-2.

29. Shimada M, ljichi H, Yonemura $Y$, et al. The impact of splenectomy or splenic artery ligation on the outcome of a living donor adult liver transplantation using a left lobe graft. Hepatogastroenterology. 2004;51(57): 625-9.

30. Ikegami T, Toshima T, Takeishi K. Bloodless splenectomy during liver transplantation for terminal liver diseases with portal hypertension. J Am Coll Surg. 2009;208(2):e1-4

31. Lo CM, Liu CL, Fan S. Portal hyperperfusion injury as the cause of primary nonfunction in a small-for-size liver graft-successful treatment with splenic artery ligation. Liver Transplant. 2003;9(6):626-8.

32. Presser N, Quintini C, Tom C, et al. Safety and efficacy of splenic artery embolization for portal hyperperfusion in liver transplant recipients: a 5-year experience. Liver Transpl. 2015;21(4):435-41.

33. Okabe H, Yoshizumi T, Ikegami T, et al. Salvage splenic artery embolization for saving falling living donor graft due to portal overflow: a case report. Transplant Proc. 2016:48(9):3171-3.

34. Lee SG, Moon DB, Ahn CS, et al. Ligation of left renal vein for large spontaneous splenorenal shunt to prevent portal flow steal in adult living donor liver transplantation. Transpl Int. 2006;20(1):45-50.

35. Kim B, Kim KW, Song GW, Lee SG. Portal flow steal after liver transplantation. Clin Mol Hepatol. 2015;21(3):314-7.

36. Horrow MM, Phares MA, Viswanadhan N, Zaki R, Araya V, Ortiz J. Vascular steal of the portal vein after orthotopic liver transplant: intraoperative sonographic diagnosis. J Ultrasound Med. 2010;29(1):125-8.

37. Sanada $Y$, Mizuta $K$, Urahashi T, et al. Impact of posttransplant portosystemic shunts on liver transplantation. World J Surg. 2012;36(10):2449-54

38. Botha JF, Langnas AN, Campos BD, et al. Left lobe adult-to-adult living donor liver transplantation: small grafts and hemi-portocaval shunt in the prevention of small for size syndrome. Liver Transplant. 2010;16(5):649-57.

39. De Carlis L, Del Favero E, Rondinara G, et al. The role of spontaneous portosystemic shunts in the course of orthotopic liver transplantation. Transpl Int. 1992;5(1):9-14.

40. Yoshizumi T, Taketomi A, Soejima Y, et al. The beneficial role of simultaneous splenectomy in living donor liver transplantation in patients with small-for-size graft. Transpl Int. 2008;21(9):833-42.

41. Wang $H$, Ikegami $T$, Harada $N$, et al. Optimal changes in portal hemodynamics induced by splenectomy during living donor liver transplantation. Surg Today. 2015;45(8):979-85.

42. Ikegami T, Shirabe K, Soejima Y, et al. Strategies for successful left-lobe living donor liver transplantation in 250 consecutive adult cases in a single center. J Am Coll Surg. 2013;216(3):353-62.

43. Ikegami $T$, Shirabe $K$, Yoshizumi $T$, et al. En bloc stapling division of the gastroesophageal vessels controlling portal hemodynamic status in living donor liver transplantation. J Am Coll Surg. 2012;214(6):e53-6.

44. Ito K, Akamatsu N, Ichida A, et al. Splenectomy is not indicated in living donor liver transplantation. Liver Transplant. 2016;22(11):1526-35. https:// doi.org/10.1002/lt.24489.
45. Moon DB, Lee SG, Hwang S, et al. Splenic devascularization can replace splenectomy during adult living donor liver transplantation - a historical cohort study. Transpl Int. 2019;32(5):535-45.

46. Ikegami T, Yoshizumi T, Tsutsui $Y$, et al. Extensive thrombectomy as a legitimate strategy in living donor liver transplantation with advanced portal vein thrombosis. Liver Transplant. 2019;25(12):1768-77.

47. Baimakhanov Z, Soyama A, Takatsuki M, et al. Effective balloon-occluded retrograde transvenous obliteration of the superior mesenteric vein-inferior vena cava shunt in a patient with hepatic encephalopathy after living donor liver transplantation. Clin J Gastroenterol. 2014;7(4):342-5.

48. Koconis KG, Singh $H$, Soares $G$. Partial splenic embolization in the treatment of patients with portal hypertension: a review of the english language literature. J Vasc Interv Radiol. 2007;18(4):463-81.

49. Zhang L, Zhang Z-G, Long X, Liu F-L, Zhang W-G. Severe complications after splenic artery embolization for portal hypertension due to hepatic cirrhosis. Risk Manag Healthc Policy. 2020;13:135-40.

50. Ishizaki Y, Kawasaki S, Sugo H, Yoshimoto J, Fujiwara N, Imamura H. Left lobe adult-to-adult living donor liver transplantation: should portal inflow modulation be added? Liver Transplant. 2012;18(3):305-14.

\section{Publisher's Note}

Springer Nature remains neutral with regard to jurisdictional claims in published maps and institutional affiliations.

\section{Submit your manuscript to a SpringerOpen ${ }^{\circ}$ journal and benefit from:}

- Convenient online submission

- Rigorous peer review

- Open access: articles freely available online

- High visibility within the field

- Retaining the copyright to your article

Submit your next manuscript at $>$ springeropen.com 